\title{
BMJ Open Factors influencing communication and decision-making about life-sustaining technology during serious illness: a qualitative study
}

\author{
Jennifer Kryworuchko, ${ }^{1}$ P H Strachan, ${ }^{2}$ E Nouvet, ${ }^{3} \mathrm{~J}$ Downar, ${ }^{4} \mathrm{~J} \mathrm{~J}$ You $^{5}$
}

To cite: Kryworuchko J, Strachan $\mathrm{PH}$, Nouvet $\mathrm{E}$, et al. Factors influencing communication and decisionmaking about life-sustaining technology during serious illness: a qualitative study. BMJ Open 2016;6:e010451. doi:10.1136/bmjopen-2015010451

- Prepublication history for this paper is available online. To view these files please visit the journal online (http://dx.doi.org/10.1136/ bmjopen-2015-010451).

Received 4 November 2015 Revised 10 February 2016 Accepted 19 February 2016

CrossMark

For numbered affiliations see end of article.

Correspondence to Dr Jennifer Kryworuchko; jennifer.kryworuchko@ubc.ca

\section{ABSTRACT}

Objectives: We aimed to identify factors influencing communication and decision-making, and to learn how physicians and nurses view their roles in deciding about the use of life-sustaining technology for seriously ill hospitalised patients and their families.

Design: The qualitative study used Flanagan's critical incident technique to guide interpretive description of open-ended in-depth individual interviews.

Setting: Participants were recruited from the medical wards at 3 Canadian hospitals.

Participants: Interviews were completed with 30 healthcare professionals ( 9 staff physicians, 9 residents and 12 nurses; aged 25-63 years; $73 \%$ female) involved in decisions about the care of seriously ill hospitalised patients and their families.

Measures: Participants described encounters with patients and families in which communication and decision-making about life-sustaining technology went particularly well and unwell (ie, critical incidents). We further explored their roles, context and challenges.

Analysis proceeded using constant comparative methods to form themes independently and with the interprofessional research team.

Results: We identified several key factors that influenced communication and decision-making about life-sustaining technology. The overarching factor was how those involved in such communication and decision-making (healthcare providers, patients and families) conceptualised the goals of medical practice. Additional key factors related to how preferences and decision-making were shaped through relationships, particularly how people worked toward 'making sense of the situation', how physicians and nurses approached the inherent and systemic tensions in achieving consensus with families, and how physicians and nurses conducted professional work within teams. Participants described incidents in which these key factors interacted in dynamic and unpredictable ways to influence decision-making for any particular patient and family.

Conclusions: A focus on more meaningful and productive dialogue with patients and families by (and between) each member of the healthcare team may improve decisions about life-sustaining technology. Work is needed to acknowledge and support the
Strengths and limitations of this study

- The qualitative component of the mixed method DEClsion-making about goals of care for hospitalised meDical patiEnts study adds depth to the understanding of contextual elements that influenced the engagement of healthcare professionals, patients and families in communication and decision-making about life-sustaining technology.

- Flanagan's critical-incident technique was an effective mechanism to elicit the broadest range of experiences experienced by participants; however, further research is needed to establish the frequency of experiences in the range.

- We interviewed participants in their native language (English or French), and integrated interviews for analysis in the language provided. Translation of French language quotes was only carried out if they were included in research reports.

- Participants included healthcare professionals most likely to be involved in communication and decision-making about life-sustaining technology, however, understanding could be strengthened by including perspectives of social workers, clinical ethicists and others who work with patients and families in the hospital in future research.

non-curative role of healthcare and build capacity for the interprofessional team to engage in effective decision-making discussions.

\section{INTRODUCTION}

Seriously ill hospitalised patients and their families should be engaged in decisions about their healthcare in order to ensure that their care meets their needs and preferences. Further, such engagement optimises patient health. For example, patients who were engaged in decisions experienced less 
anxiety and depression, less fatigue, and had higher overall quality of life, physical and social functioning, and have better control of diabetes and hypertension. ${ }^{12}$ As the end of life approaches, decisions about the use of life-sustaining technologies (such as cardiopulmonary resuscitation, ventilators, dialysis or intensive care unit admission) are implemented for seriously ill patients. However, communication about these treatment options is often poor, and many patients receive care that is inconsistent with their values and preferences. ${ }^{3}$ Many authors have described interventions aimed at improving patient/family engagement and improving the match between patient preferences and care delivered, ${ }^{4-14}$ but these have often been ineffective or poorly adopted outside of the studies where they are tested. The mismatch between patient preferences and the care provided at the end of life (a "preference misdiagnosis') occurs when healthcare professionals make a decision about treatment without integrating the informed preferences and priorities of their patients. ${ }^{15-17}$ A preference misdiagnosis has important implications for a patient's quality of life and end-oflife care.

In the context of a broader research programme to improve end-of-life care for seriously ill patients, we conducted a mixed-methods study called DECIsion-making about goals of care for hospitalised meDical patiEnts (DECIDE). The study involved a cross-sectional survey of physicians and nurses from the acute medical inpatient ward setting of 13 hospitals in five Canadian provinces, as well as open-ended qualitative interviews with physicians and nurses from three of these hospitals. ${ }^{18}$ The mixed-methods design sought to understand factors which affect communication and decision-making about life-sustaining technology from the perspectives of healthcare providers, and offer suggestions for potential solutions, through the collection of complementary quantitative and qualitative data.

The quantitative component of DECIDE found that a range of professionals (ie, nurses and social workers) supported key decision-making activities, such as initiating discussions and decision coaching. Participating healthcare providers felt it was most acceptable for staff physicians to make the final determination about the use or non-use of life-sustaining technology with patients and their families. Physician and nurse participants related that family-related and patient-related factors were the most important barriers, whereas barriers related to their skills and system factors were relatively less important. ${ }^{18}$

In this qualitative component, we sought to provide richer, more nuanced data than what could be obtained through the survey methods. Specifically, we aimed to explore physicians' and nurses' experiences, with a view to identifying rich description of their roles and factors influencing communication and decisionmaking with seriously ill hospitalised patients and their families.

\section{METHODS}

\section{Study design}

The qualitative study used Flanagan's critical incident technique (CIT) and interpretive description of openended interviews. ${ }^{19}{ }^{20}$ Interviews were conducted between 2012 and 2013 with staff physicians, residents and nurses $(\mathrm{n}=30)$ who provide care to patients admitted to the acute medical inpatient ward at one of three large Canadian hospitals. The goal of CIT is to explore specific incidents with those who have lived them, and to uncover assumptions, values or impacts that participants may not themselves appreciate. Strengths of the CIT are that it commonly elicits very effective or very ineffective practices, and aims to provide findings that are highly focused on solutions to practical problems. ${ }^{21}$

\section{Setting and participants}

Qualitative study participants were purposively recruited at hospitals from three Canadian provinces (Ontario, Quebec and Alberta) and included English-speaking and French-speaking facilities for a more nationally representative sample. Eligible professionals for inclusion were staff physicians, residents and nurses who cared for seriously ill patients and their families in the acute medical inpatient ward setting, which are patient care units where patients with non-surgical serious illnesses are admitted when they cannot be managed in the outpatient setting. The acute medical inpatient wards typically have 35-45 ward beds (nurse to patient ratios 1:4 to $1: 8$, depending on the complexity of patient care needs) and a small close-observation or telemetry unit, for acute continuous monitoring of vital signs (nurse to patient ratio 1:2). An interprofessional team cares for patients with acute medical conditions, often stemming from a wide range of complex medical problems including diabetes, stroke, pneumonia, chronic obstructive pulmonary disease, heart failure, sepsis and multisystem failure. Patients on such units may receive inpatient intermittent haemodialysis or non-invasive mechanical ventilation (continuous positive airway pressure CPAP) via face or nasal mask, however, unstable patients may be transferred to intensive care unit for more intensive management. Participant recruitment took place in parallel with and aided by the DECIDE quantitative (questionnaire-based) study. Professionals received an email about the study and indicated their willingness to participate in a subsequent individual interview in the quantitative DECIDE survey. We selected participants to ensure balanced representation among the three hospital centres, between nurses and physicians, men and women, and among clinicians with diverse levels of experience. We obtained research ethics board approval at each participating site; all participants gave informed consent before taking part.

\section{Data collection}

Individual interviews at all sites were conducted by the same experienced qualitative interviewer in a location of 
the participant's choice (a private room located close to the hospital ward or in their home). Each participant provided one audio recorded interview lasting between 27 and $91 \mathrm{~min}$ (mean $47 \mathrm{~min}$ ). The interviewer used a standard introduction and set of questions, and the research team added additional prompts as the interviews progressed (box 1). During the in-depth interviews, participants were invited to describe specific encounters with patients and families in the acute medical inpatient ward setting in which discussions about the use or non-use of life-sustaining technology went particularly well and unwell (ie, critical incidents). We further explored participants' perceptions of professional roles and the context and challenges encountered by healthcare professionals, patients and their families. The interviewer wrote detailed field notes, to record what stood out for her, immediately after each interview. We transcribed audio-recorded interviews verbatim and audited transcripts for accuracy. Both transcripts and field notes were organised in NVIVO 10 to facilitate data management.

\section{Analysis}

The team developed a codebook by reviewing critical incidents to code them inductively into themes.

\section{Box 1 Interview guide with prompts}

Interview introduction: 'Communication and decision-making about goals of care includes decisions about the use of lifesustaining technologies at the end of life, such as cardiopulmonary resuscitation, ventilators, dialysis or intensive care unit admission.

Can you tell me of an experience you have had with a patient or their family in which communication and decision-making about goals of care and the use of life-sustaining technologies went particularly well?

Can you tell me of an experience you have had where communication and decision-making about goals of care and the use of life-sustaining technologies did not go well?'

Examples of prompts

1. About critical incident: What in particular defines this experience for you as a good/bad one? What made it easy/difficult? Where was this happening? What happened in this case? What was the outcome?

2. About participant role: What was your role in any meetings with the patient or their family? Is it normal for you to play this role? Did you do anything to get yourself, other members of the medical team, the family or the patient ready for discussing or deciding on goals of care?

3. About others' roles: What other members of the medical team were involved in the discussion(s) of goals of care and the use of life-sustaining technologies in this case? What were their roles? How did they become involved? What role does the nurse or do the nurses play, in your experience? Are nurse usually informed of upcoming family meetings?

4. About factors influencing decision-making: Are there certain circumstances that make discussions about goals of care or lifesustaining technologies particularly difficult, either for you or for the patient or their family?
We coded the data, and met frequently to discuss, challenge and make decisions about codes and to interpret emerging findings. We further refined interview questions and prompts for subsequent interviews using synchronous distance technology (Skype) after each set of two or three interviews. We integrated all passages into the coding framework in their native language. In particular, two bilingual investigators analysed French interviews. Translation of specific representative quotes into English, preserving the participant's meaning, was carried out by the researchers only to communicate results in written English communication/publications. We worked together in an analytic process that involved synchronous and asynchronous meetings to reflect on the evolving conceptual framework in light of new interview data and increased immersion in the data. The draft code book evolved throughout the study and included key themes, subthemes and their definitions. The names and descriptions of key themes changed, collapsed and expanded based on new data, and considering the context of previous data. The four factors presented here represent key themes in the interview data, subthemes are described as they relate to each of the key themes. We found that while participants' accounts reflected their different perspectives based on their different levels of experience and professional identities, certain key themes were prominent across participant categories (12 nurses, 9 residents and 9 staff physicians).

Saturation is achieved when adding 100 critical incidents to the sample contributes only 2 or 3 more themes to the analysis. ${ }^{19}$ In our study, a total of 30 interviews conveyed data about 120 critical incidents (mean 4 , range 2-9 critical incidents). We considered the data categories had reached saturation since the first four interviews provided 18 critical incidents, and all but two themes, to the description of factors influencing communication and the decision-making process; the remaining 26 participants described a further 102 critical incidents. We did not add new themes to the analysis in the last 20 interviews.

In summary, we used constant comparative methods combining independent and then group analysis. Auditing by a team member external to original analysis ensured themes fit with data. We continued until analysis indicated we had reached saturation.

\section{RESULTS}

A total of 30 individuals participated, 10 from each of three inpatient medical teaching units (Quebec, Ontario and Alberta): 9 staff physicians, 9 residents and 12 nurses (table 1). Participants were 25-63 years old (mean 39 years), and mainly women (73\%)-a distribution skewed by the high representation of female nurses (11 out of 12 in the study).

We found that several key factors influenced communication and decision-making about life-sustaining 
Table 1 Participant demographics

\begin{tabular}{lllll}
\hline Characteristics & Staff physicians $(\mathbf{n}=\mathbf{9})$ & Residents $(\mathbf{n}=\mathbf{9})$ & Nurses $(\mathbf{n = 1 2})$ & Total $(\mathbf{n = 3 0})$ \\
\hline $\begin{array}{l}\text { Female } \\
\text { Experience (years) }\end{array}$ & $6(67 \%)$ & $5(55 \%)$ & $11(92 \%)$ & $22(73 \%)$ \\
$\quad 55$ & $2(22 \%)$ & $9(100 \%)$ & $4(33 \%)$ & $15(50 \%)$ \\
$5-10$ & $0(0 \%)$ & $0(0 \%)$ & $3(25 \%)$ & $3(10 \%)$ \\
$10+$ & $7(78 \%)$ & $0(0 \%)$ & $5(42 \%)$ & $12(40 \%)$ \\
Hospital & & & & \\
Ontario & $3(33 \%)$ & $3(33 \%)$ & $4(44 \%)$ & $10(33 \%)$ \\
Alberta & $3(33 \%)$ & $4(44 \%)$ & $3(25 \%)$ & $10(33 \%)$ \\
Quebec & $3(33 \%)$ & $2(22 \%)$ & $5(42 \%)$ & $10(33 \%)$ \\
\hline
\end{tabular}

technology. The overarching factor was how people conceptualised the goals of medical practice. Other factors related to how a patient or family's choice was shaped by their relationships, particularly how people worked towards 'making sense of the situation', how physicians and nurses approached the inherent and systemic tensions in achieving consensus with families, and how professional work regarding end-of-life issues was conducted within acute medical unit teams (table 2). These contextual elements influenced the engagement of healthcare professionals, patients and families, and had significant implications for the quality of communication and decision-making about the use of life-sustaining technology. Participants described incidents in which these factors interacted in dynamic and unpredictable ways to influence decision-making for any particular patient and family.

Factor 1: conceptualisations of medical practice as 'saving lives and warding off death'

Death and dying were spoken of as largely a culturally taboo topic in hospitals. Participants' attitudes towards end-of-life communication and decision-making reflected a dominant cultural, economic construction of hospitals, doctors, medicine, as primarily about saving lives: warding off death, not overseeing the dying (table 2). Participants' descriptions reflected a general assumption on their part and the part of patients and families that patients were admitted for hospital care to regain health, not to die. Care continued under this

Table 2 Conceptualisations of medical practice as 'saving lives and warding off death'

\section{Description \\ Dominant cultural, economic construction of hospitals, doctors, medicine as being officially about saving lives: warding off death, not overseeing the dying.}

Discussions avoided until life-saving was not possible or death occurred

Discussions focused on 'getting the DNR'

Professionals' identity wrapped up in ideas of saving lives

\section{Examples}

'I think one of the things that's important is we go into this profession and, you know, doctors it's all about we need to fix things, and we need to, you know, cure things. That's kind of the mindset we have. And we sometimes lose sight of the fact that we can't actually fix everything.' (Staff physician)

'It's as though for the physicians it's always life at any cost. Always. They are always focused on saving lives. Death is like a failure. It's not something we talk about.' (Nurse)

'One of the daughters was angry. She was saying we were abandoning her mother. That we weren't allowed to do that. That we had to keep it up until the end.' (Nurse) 'It's usually a pretty clear next step. Like the person is probably hours from dying and they change them to comfort [care]. Often it's that close.' (Nurse)

'A lot of times when the physician is having that conversation on a medical unit, it's when things have gone badly, when things have changed, when the patient is doing poorly so the family is really distressed about how their family member is doing.' (Nurse)

'I think we get task oriented. We want to get to a goal of care because we think it's appropriate, and we just want enough from the patient to justify in our own minds that they're in agreement with that. And I'm not sure, in an informed consent way, that that's enough.' (Staff physician)

'The residents say "She's really sick, and she's not doing well."' "Yeah, but we're doing everything. We are doing everything, and the rest is because the person is failing. It's not because we're failing." So changing that mindset from we should be able to cure everybody all the time, and nobody should ever die which is crazy, right? Doesn't make sense.' (Staff physician)

DNR, do-not-resuscitate. 
assumption until death was imminent. Importantly, participants described a norm of discussions being avoided until doctors (and sometimes nurses) recognised that life-saving interventions were increasingly futile and that death could not be postponed. Physicians and nurses characterised communications with patients or more often families as difficult and stressful, when they felt the urgency to communicate with families primarily to prevent delivery of futile care. Discussions about lifesustaining technology at such late points in the patient's life (or illness) focused on 'getting the DNR [do not resuscitate]' (resident physician), and writing it in the chart.

Throughout the interviews, many participant accounts conveyed existential issues with regards to witnessing suffering and managing the dying patient, and the perceived failure of medical expertise. Mainly, since such discussions were equated with death and dying, healthcare professionals often waited to have these decisionmaking conversations until there was, in their words, 'nothing to be done' for the patient. When this happened, the timing of communication resulted in disclosure that the patient was almost certainly dying.

\section{Factor 2: work towards 'making sense of the situation'}

We found that 'making sense of the situation' was work and a process that was essential to advancing decisionmaking (table 3). Participants described progress in decision-making as contingent on having been able to make sense of a patient's situation. Work towards 'making sense of the situation' involved a process of establishing a relationship, knowing them over time and integrating information about the patient's health and treatment options with (ideally the patients') illness beliefs and (ideally the patients') goals of care. In cases that went well, dialogue with patients and/or families created opportunities to construct a shared understanding of the patient's situation and the use of lifesustaining technology. A perceived failure to be emotionally ready for discussions or to make sense of the situation caused patients, families and/or healthcare professionals to 'get stuck' and be unable to progress towards a decision. This contributed to delays in even initiating decision-making, and was perceived by nurses as a missed opportunity to ease patient and family suffering.

In their examples of discussions that went well, both physicians and nurses saw it as their role to facilitate this process. They described work helping patients and families understand the complex situations they were facing, helping them make sense of responses to treatments, and clarifying messages given by other members of the team. When physicians struggled to make sense of the situation, often due to uncertainty about prognosis or the reversibility of the patient's condition, they delayed initiating the decision-making process. Both physicians

Table 3 Work towards 'making sense of the situation'

\section{Description}

Focus on getting to know the patient and

their personal life story

Recognising that the patient has a unique interpretation of what is happening, and what a 'correct' course of action might be is individual

Work helping patients and families understand the complex situations they were facing, helping them make sense of responses to treatments, and clarifying messages given by other members of the team.

Experiencing moral distress related to different perspectives about the importance of prognosis or the value of suffering

To make a recommendation for care, healthcare professionals also needed to establish meaning.

\section{Examples}

'We know everything medically about them, but we don't know their story and we don't know what informs the decisions they've made to this point and sometimes it can be as simple a thing as they had a really bad illness when they were young, and they got better, therefore they're going to get better this time.' (Resident physician)

'We're not the patient and although we have our own opinion about what is the best thing to do but regardless that's...you know, the goal should be to try to make the patient make the decision with our help in terms of trying to choose the best thing.' (Resident physician)

'They've just been told something potentially devastating. So you've got to ask how much they actually retained. So that's usually the best place. So gleaning a bit of an insight into what they understand, what they retain, what this means to them or what they're understanding it means, is probably the biggest step for the nurse to take after they've had that change.' (Nurse)

'I went in, and I saw the patient and I literally had tears in my eyes. It's like oh my gosh, I cannot believe that this body still has a soul living in it because it was terrible. And yet I wanted to be very respectful of the decision-maker who I thought had a very valid perspective. So there's that conflict sometimes of perspective. I think I realise people just need time to absorb things.' (Staff physician)

'Sometimes it's denial; sometimes it's that we don't have time or sometimes it's about us, we're not comfortable making that decision either. If we aren't... if I am not sure of the prognosis, if I think they might get better through some intervention, but at the same time there's other factors, like the intervention is pretty invasive, then in those cases [we delay the decision].' (Resident physician) 
and nurses reported experiencing moral distress related to different perspectives about the importance of prognosis or the value of suffering.

\section{Factor 3: inherent and systemic tensions in achieving consensus about the goal of care}

An important contextual factor was that, in the face of patient suffering and imminent death, participants perceived that patients and families were emotional, even irrational at times. Patients and families were defined as 'difficult' based on what physicians and nurses saw as their inability to understand or accept the situation. Further, being difficult was linked to a failure to come quickly on board with the plan the physician saw as ethically and clinically appropriate. Engaging such patients and families in the decision-making process could be particularly challenging. Nurses who were left behind with patients and families in the wake of heated discussions between physicians and patients wanted more strategies for managing their stress and for speaking to stressed families.

In addition to the stress and challenges that are inherent to achieving consensus among patient, family and their healthcare team about the use of life-sustaining technology (table 4), our data points to systemic limitations to consensus building and shared decision-making with patients and families. Achieving consensus is intricately interwoven with 'making sense of the situation' (described above). Making sense of a situation requires some reflection and processing of information.
The invitation to patients and families to make sense of dying is routinely occurring when active care has already been determined by healthcare team members to be futile; this can be very late. As noted above (factor 1), situations described as challenging revealed that healthcare professionals tended to flag patients as urgently requiring goals of care discussions when patients were beyond rescue and often facing imminent death.

In cases where participants described a team-based approach to communication and decision-making, participants prioritised 'getting on the same page' to establish agreement within the team, before engaging patients and families. Team discussion focused on ensuring all relevant information was gathered before a discussion with family, and was emphasised as important to avoid patients and families being exposed to conflicting messages. The problem is that where goals of care communication and decision-making are occurring within such a compressed time frame, as seems to be the norm at study sites, patients and families may have even less time than healthcare team members to make sense of circumstances and, thus, meaningfully engage in decision-making. Such conditions could render patients and families emotional, irrational or 'difficult'. Moreover, one can presume it would be more difficult for healthcare team members to defuse stressful communications when they are themselves feeling pressure to adjust the patient's care plan before the patient dies and/or is exposed to futile measures.

Table 4 Inherent and systemic tensions in achieving consensus

Description
Easy decisions were preceded/
accompanied by work 'making meaning'
together
Perceived failure to progress towards

meaning making or be emotionally ready for discussions led to delays in (initiating) potentially supportive discussions and decision-making.

Holding strong opinions contributed to less discussion and dialogue, ultimately making it harder to reach agreement.

Working at cross-purposes with patient's priorities and goals.

\section{Examples}

'It's easy when everyone is thinking the same thing.' (Staff physician)

'I had numerous conversations with the family, the husband particularly; it was his wife that was sick and very ill. He made a lot of comments that this person was his life and he couldn't live without her and all these things and so I started to wonder if we were more treating him instead of her for her symptoms. Anyway there was never any discussion over the next few weeks of goals of care, and they kept treating her and treating her and treating her. And I understand then, maybe two or three weeks after, then she coded, and she died later that day. I had had some struggles talking to the doctors that I worried if we hadn't broached the subject ahead of time then we weren't really helping to treat or ease this man's grief or the patient's suffering.' (Nurse)

'It becomes more problematic when people are demented, and you've got, I think it's less common now, but I ran into a public guardian once who would not change the level of care in those days and I resigned from the case, told them to get another doctor because I thought it was inhuman keeping an absolute vegetable alive, you know.' (Staff physician)

'There was one time when neither the family nor the patient wanted any aggressive care. She was really not doing well. She had spoken clearly, as had her family. I had to call the physicians back in because we had been told to kick off a battery of antibiotics, take blood, get tests, this, that, and the family was not happy. And the physicians told them that it was pneumonia, that it was reversible which is why they were proceeding the way they were. But the family and the patient didn't want that.' (Nurse) 
What seems to be key here, is that when communications with families did not go well, most nurses and physicians did not have the experience and skill set to unblock tense disagreements, nor did they have much time to do so. Not surprisingly, participants defined as easy those decisions where both healthcare professionals and the patient and their family had constructed the same meaning about the situation before a patient arrived in hospital or before a discussion: 'It's easy when everyone is thinking the same thing' (staff physician).

\section{Factor 4: approaches to professional work within teams}

In their examples of critical incidents, participants contrasted a 'team-based approach' with the 'solitary nature' of professional work. Overall, the institutional/practical construction of communication and decision-making about life-sustaining technology was solitary and physician centred (table 5). While some participants described instances of a team-based approach for a specific individual patient, a majority of participants perceived communications as the physicians' responsibility as opposed to a team responsibility. Participants described physicians who largely worked alone and asynchronously from other team members to prepare, inform and guide patients and families through decision-making. Leading emotional end-of-life discussions alone placed a great deal of pressure on physicians, especially residents.

Descriptions of nursing work were largely absent in physicians' narratives, even when invited to reflect on nurses and other health professionals' roles. For most participants, work done by nurses was not recognised as contributing to communication and decision-making about life-sustaining technology (even for nurses themselves). Nurse participants described their work as happening asynchronously around physicians' encounters. They described preparing the groundwork for physicians' discussions about life-sustaining technology, as well as 'picking up the pieces' after physicians delivered unexpected prognostic news and decisions.

Most participants highlighted their recognition of the value of team-based approaches to goals of care communication and decision-making. Nurses and residents continue to feel isolated in the work they did connected to goals of care discussions. Where residents acknowledged the importance of more training, a number of nurses felt it would be beneficial to patients for nurses to be more fully informed and even included in physician-led goals of care discussions with patients and family. Mentorship, modelling and support to develop the necessary skills to engage patients and families in productive discussions were frequently raised by participants. Most physicians are well prepared for 'breaking bad news', but less so for 'breaking bad news' to patients and families who were too distressed to listen to a 15 min presentation and recommendation of care. More experienced physicians shared strategies to help patients and families be ready for these discussions. For example, two physicians in different cities advocated for a 'stepwise' approach. They gently planted the seeds that a decision would soon need to be taken by commenting on the patient's declining health. They emphasised to

Table 5 Approaches to professional work within teams

Description Examples

Working alone to prepare and inform and guide patients.

Reacting to (non) decision-making discussions, rather than working together to support and create conditions for dialogue.

Feeling unprepared for challenging discussions about existential issues and end of life.

Nurses remain in the background, behind the scenes.
'Everybody [patient and family] went with me to the quiet room... And I just spoke to all of them, like giving a speech.' (Resident physician)

'... I was sort of leading the meeting and the neurologist was just somewhat of a Silent Sam, just allowing me to lead the discussion and not offering a whole lot in the way of support or guidance, which was frustrating because patients who have this condition, this is how the condition goes. By and large this is how their life ends.' (Staff physician)

'Often we are picking up the collateral damage of non-decision-making, of non-discussions. Now things are really not going well. A decision needs to be taken right now. So we are more often in that mind frame. It's rare that we are ahead of the ball.' (Nurse)

'And I can say this with certainty, that there are people, and l've seen it with colleagues as well as students, who are afraid of this: who are afraid of talking about anything related to end of life with people.' (Staff physician)

'I will usually stand behind the curtain and not go on the other side of the curtain and be present with the conversation that's happening. I'll just listen. I won't be a contributor in that conversation. I don't know why I do that.' (Nurse)

'It's usually always been the physician that has that conversation and then we just, reinforce the conversation afterwards.' (Nurse)

'It's out of my hands whether or not it's taken into consideration or not. You can tell residents all they want but if they have something set in their mind that this is going to happen then that's going to happen. Most of the times we can't change their minds. But you never know.' (Nurse) 
their residents that patients and families needed time to adjust to a prognosis. Another physician stressed the importance of being present for these conversations: turning the phone off, putting time aside for this serious conversation, and listening to what the patient or family had to say. Many senior physicians explicitly included junior residents in discussions about the use or non-use of life-sustaining technology. They knew that residents experienced more stress in these conversations, and required particular abilities to listen to, and respond to, families.

\section{DISCUSSION}

The evolution of decision-making about life-sustaining technology for any particular patient was influenced by social constructions of medical practice as life-saving, an existential and practical need to 'make sense of the situation' together, inherent and systemic tensions in achieving consensus, and the solitary nature of professional practice in the medical teaching unit. Indeed, it seemed that three conditions were present for a decision that 'went well': (1) the patient needed to be beyond rescue, (2) the 'correct' option needed to be clear to healthcare professionals, patients and families, who also needed (3) to agree about goals of care and the interventions that should be used to achieve those goals. Unfortunately, these three conditions are rarely present in the medical ward setting. Prognosis is hard to establish for seriously ill patients, ${ }^{22}$ and physician perceptions of prognostic certainty affect the timing of decision-making. ${ }^{23}$

The social construction of medical practice as 'saving lives and warding off death' reported by participants in this study, has significant implications for the quality of communication about life-sustaining technology. First, the presumption within such a construction of medical practice is that a life-saving focus is logical and, by default, in the patient's best interest. This is contrary to evidence that shows that at the end of life, palliative care approaches result in the same or better quality of care and better health outcomes than high-intensity and costly life-sustaining technology care. ${ }^{24}$ Essentially, what is important to note is that with an equation of medical care as life-saving care, warding off death dominates decision-making in the hospital ward. Only when death cannot be warded off, is communication with patients and families about goals and end-of-life care needed, and this is communication aimed primarily at preventing life-sustaining care, which at that point is considered futile. ${ }^{25}$ Preventing delivery of futile care is a providercentred problem, and is intensified for healthcare professionals for whom death becomes personal and uncomfortable.

Our findings echo other studies that have found that while patients and families desire involvement in decision-making, ${ }^{26} 27$ they are seldom presented with alternatives to life-sustaining technology. ${ }^{28}$ Framing alternatives as 'there was nothing to be done' corresponds to the social construction of medical practice as 'saving lives and warding off death'. Such wording perpetuates the assumption that non-lifesaving care is equivalent to failure or abandonment. ${ }^{29}$ We caution that language such as 'nothing to be done' is unhelpful, in that it frames non-aggressive healthcare, including nursing care, pain management and palliative care, as nothing. This leaves little room for strategising, valuing and improving the work that is involved in comfort care. Reframing this message to what we can provide is critical to conveying to patients and families that we will not abandon them.

While clinicians felt it was crucial to know a patient's code status to prevent futile care, this may be a low priority for patients/families. A focus on more meaningful and productive dialogue with patients and families is needed. We found that work toward 'making sense of the situation' was central to the decision-making process, and was most effective (ie, incidents that went well) when dialogue occurred with others. Establishing relationships with patients and families is a key element of the process, and occurred alongside the process of meaning-making. Participants' narratives described the search for meaning in the situation by healthcare professionals, patients and families. Individual understandings of circumstances and opportunities for health were developed in dialogue with patients and families and their healthcare professionals (or between healthcare professionals). We suggest that work 'getting everyone on the same page' should fully involve patients and their families. The quantitative survey results of the larger DECIDE mixed-method study, ${ }^{18}$ which highly ranked patient/family related barriers as impeding communication and decision-making, are reflected in the stories of patients and families who struggled to make sense of the decision and context they were facing. And, since it is likely that patients and families will experience grief and loss with changing health status, ${ }^{30}$ we should expect that for patients and families, making sense of illness will require time and support from their healthcare team. By contrast, we found that the heavy result-oriented agenda inherent in 'getting the DNR' seemed to abbreviate communication and minimise the engagement of patients and families. This important dialogue should not be rushed or hurried to 'get a code status', especially when the box checked on the order sheet has such enormous implications for the patient's future wellbeing. We suggest that an organised approach to supporting early dialogue between healthcare professionals, patients and their family members is needed; shared decision-making facilitates the integration of information about options with the patient's values and preferences. ${ }^{31} 32$ We know that such dialogue occurs in complex environments, where listening to the patient and their family is essential to providing care that fits best for each person at the end of life. ${ }^{13}$ 33-39 While some of the findings are known from research in critical care settings (eg, the importance of supporting 
team-based approaches or structured family involvement),${ }^{40-45}$ the acute medical ward setting is very different (eg, lower nurse patient ratios, more daily admissions and discharges). Additionally, patients are more likely to be able to participate in decision-making than patients in critical care settings. Taken together, features of the acute medical ward setting may necessitate different strategies to optimise patient and family engagement.

Overall, there was an impoverished understanding of the potential for interprofessional practice. While our earlier survey findings described the perception that everyone could get involved, ${ }^{18}$ qualitative findings suggest that this is not yet happening. Participants described usual conditions in which they tended to work in isolation from other professionals and were unclear about each others' roles. While other professionals' roles were invisible to most participating physicians, nurses could articulate related nursing work. Overwhelmed physicians believed that they worked alone with patients and families throughout the decision-making process, which is consistent with other research in the medical teaching unit setting. ${ }^{46}$ However, interprofessional collaboration can decrease professionals' distress, ${ }^{47}$ and therefore, it is possible that interprofessional collaboration in decision-making could maximise the opportunity to share the emotional burden of providing care, and to receive support from colleagues. Identifying optimal team roles may be an important first step in developing an intervention tailored to the clinical setting that would support patients, families and health providers in navigating this necessary, yet emotionally challenging territory.

A number of key factors speak to the importance of better supporting resident physicians in the acute medical ward setting. Medical residents experience varying levels of supervision for a whole range of clinical activities (not just for DNR orders) from one staff physician or one institution to the next, and depending on personal/local practice patterns. Further, their competence is assessed on a continuum as they become more autonomous to make important decisions; there is not a 'gold standard' criteria for declaring a junior resident as being 'competent' to lead decision-making about the use of life-sustaining technologies. A combination of these and other factors may lead to situations where relatively inexperienced physicians are having end-of-life discussions on their own. Strategies that better support resident physicians (and others) in the acute medical ward setting were welcomed and suggested by participants in our study.

Participants shared some strategies that worked more effectively to engage patients and families-for example, making time, sharing support roles, explicitly helping families make meaning and progress in decision-making. In their stories of what went well, participants engaged with and managed conflict within interprofessional teams and during challenging family situations. In such situations, the team proactively supported patients and their families to make sense of the situation, to understand recommendations, and supported them to make decisions. Such support requires excellent communication skills, therefore like others, ${ }^{44} 4548$ we advocate for improved communication training for healthcare professionals. We also recognise that the clinical teaching unit needs an organisational culture that supports decisionmaking processes that will work under the conditions of usual practice. Institutional guidelines or standard operating procedures with linked quality indicators, might be helpful to promote an effective team-based approach to communication and decision-making for the acute medical ward setting.

Several factors may limit the transferability of this research. First, not all perspectives of healthcare professionals in the medical ward setting are represented by this work. Further research should include the views of social workers, clinical ethicists and others who work with patients and families in the hospital. Second, our results may not be transferable to other healthcare settings or other countries. We provide quotes to help readers decide whether our experience resonates with their settings.

\section{CONCLUSIONS AND RELEVANCE}

An integrative approach to decision-making about the use of life-sustaining technology, that acknowledges and supports the non-curative role of healthcare and hospitals, is needed. We must strengthen the interprofessional team's capacity to cope with and communicate about uncertainty to patients and families, discuss related existential issues, and support patients and families who are suffering as they make decisions about care in advanced serious illness. The qualitative component of the mixedmethod DECIDE study adds depth to the understanding of contextual elements that influenced the engagement of healthcare professionals, patients and families. This understanding about context is key to developing improvement strategies that harness the potential and actual roles of healthcare professionals.

\section{Author affiliations}

${ }^{1}$ Nursing and Centre for Health Services and Policy Research, University of British Columbia, and Research Scientist, British Columbia Centre for Palliative Care, Vancouver, British Columbia, Canada

${ }^{2}$ McMaster University, Hamilton, Ontario, Canada

${ }^{3}$ Humanitarian Health Care Ethics, McMaster University, Hamilton, Ontario, Canada

${ }^{4}$ Divisions of Critical Care and Palliative Care, University of Toronto and University Health Network, Toronto, Ontario, Canada

${ }^{5}$ Department of Medicine, Clinical Epidemiology and Biostatistics, McMaster University, Hamilton, Ontario, Canada

Contributors JK and PHS designed the qualitative study, analysed and interpreted data, drafted and revised the manuscript and approved the final version for publication. EN conducted interviews and analysed and interpreted the data, revised the manuscript and approved the final version for publication. JJY contributed to the design of the study, obtained funding, and both JJY and JD audited the analysis and interpreted the data, revised the manuscript and approved the final version for publication. JK, PS and EN had full access to all the data in the study and took responsibility for the integrity 
of the data and the accuracy of the data analysis. All authors agree to be accountable for all aspects of the work in ensuring that questions related to the accuracy or integrity of any part of the work are appropriately investigated and resolved.

Funding This work was supported by funding from the Canadian Institutes for Health Research grant number MOP-119516.

Competing interests None declared.

Ethics approval University of Calgary Research Ethics Board E-24741, Hamilton Integrated Research Ethics Board 11-631, Comité d'éthique de la recherche Universite de Sherbrooke 12-113.

Provenance and peer review Not commissioned; externally peer reviewed.

Data sharing statement No additional data are available.

Open Access This is an Open Access article distributed in accordance with the Creative Commons Attribution Non Commercial (CC BY-NC 4.0) license which permits others to distribute, remix, adapt, build upon this work noncommercially, and license their derivative works on different terms, provided the original work is properly cited and the use is non-commercial. See: http:// creativecommons.org/licenses/by-nc/4.0/

\section{REFERENCES}

1. Kiesler DJ, Auerbach SM. Optimal matches of patient preferences for information, decision-making and interpersonal behavior: evidence, models and interventions. Patient Educ Couns 2006;61:319-41.

2. Hack TF, Degner LF, Watson $P$, et al. Do patients benefit from participating in medical decision making? Longitudinal follow-up of women with breast cancer. Psychooncology 2006;15:9-19.

3. Heyland DK, Barwich D, Pichora D, et al. Failure to engage hospitalized elderly patients and their families in advance care planning. JAMA Intern Med 2013;173:778-87.

4. Penticuff JHP, Arheart KLP. Effectiveness of an intervention to improve parent-professional collaboration in neonatal intensive care. $J$ Perinatal Neonatal Nurs 2005;19:187-202.

5. Song MK, Donovan HS, Piraino BM, et al. Effects of an intervention to improve communication about end-of-life care among African Americans with chronic kidney disease. Appl Nurs Res 2010;23:65-72.

6. Vandervoort A, Houttekier D, Van den Block L, et al. Advance care planning and physician orders in nursing home residents with dementia: a nationwide retrospective study among professiona caregivers and relatives. J Pain Symptom Manage 2014;47:245-56.

7. Song MK, Ward SE, Lin FC. End-of-life decision-making confidence in surrogates of African-American dialysis patients is overly optimistic. J Palliat Med 2012;15:412-17.

8. Retrum JH, Nowels CT, Bekelman DB. Patient and caregiver congruence: the importance of dyads in heart failure care. J Cardiovascular Nurs 2013;28:129-36.

9. Kassam A, Skiadaresis J, Alexander S, et al. Parent and clinician preferences for location of end-of-life care: home, hospital or freestanding hospice? Pediatr Blood Cancer 2014;61:859-64.

10. Jacobs S, Perez J, Cheng YI, et al. Adolescent end of life preferences and congruence with their parents' preferences: results of a survey of adolescents with cancer. Pediatr Blood Cancer 2015;62:710-14

11. Holdsworth L, Fisher S. A retrospective analysis of preferred and actual place of death for hospice patients. Int J Palliat Nurs 2010;16:424, 426, 428 passim

12. Duncan J, Taillac $P$, Nangle $B$, et al. Electronic end-of-life care registry: the Utah ePOLST initiative. AMIA Symposium 2013;2013:345-53.

13. Aoun SM, Skett K. A longitudinal study of end-of-life preferences of terminally-ill people who live alone. Health Soc Care Community 2013;21:530-5

14. Teno JM, Hakim RB, Knaus WA, et al. Preferences for cardiopulmonary resuscitation: physician-patient agreement and hospital resource use. The SUPPORT Investigators. J Gen Intern Med 1995:10:179-86.

15. Joseph-Williams N, Elwyn G, Edwards A. Knowledge is not power for patients: a systematic review and thematic synthesis of patient-reported barriers and facilitators to shared decision making. Patient Educ Couns 2014;94:291-309.

16. Joseph-Williams N, Edwards A, Elwyn G. Power imbalance prevents shared decision making. BMJ 2014;348:g3178.
17. Mulley AG, Trimble C, Elwyn G. Stop the silent misdiagnosis: patients' preferences matter. BMJ 2012;345:e6572.

18. You JJ, Downar J, Fowler RA, et al. Barriers to goals of care discussions with seriously ill hospitalized patients and their families: a multicenter survey of clinicians. JAMA Intern Med 2015;175:549-56.

19. Flanagan JC. The critical incident technique. Psychol Bull 1954;51:327-58.

20. Norman IJ, Redfern SJ, Tomalin DA, et al. Developing Flanagan's critical incident technique to elicit indicators of high and low quality nursing care from patients and their nurses. $J$ Adv Nurs 1992;17:590-600.

21. Schluter J, Seaton $P$, Chaboyer W. Critical incident technique: a user's guide for nurse researchers. J Adv Nurs 2008;61:107-14.

22. Selby $D$, Chakraborty $A$, Lilien $T$, et al. Clinician accuracy when estimating survival duration: the role of the patient's performance status and time-based prognostic categories. J Pain Symptom Manage 2011;42:578-88.

23. Gutierrez KM. Prognostic categories and timing of negative prognostic communication from critical care physicians to family members at end-of-life in an intensive care unit. Nurs Inq 2013;20:232-44.

24. Wennberg JE, Fisher ES, Goodman D, et al. Tracking the care of patients with severe chronic illness: the Dartmouth Atlas of Health Care 2008. 1st edn. Dartmouth, NH: The Dartmouth Institute for Health Policy and Clinical Practice, Center for Health Policy Research, 2008.

25. Nouvet E, Strachan $\mathrm{PH}$, Kryworuchko J, et al. Waiting for the body to fail: a limit to end-of-life communication and decision-making. Mortality 2016. Published Online Mar 2016. doi:10.1080/ 13576275.2016.1140133

26. Heyland DK, Dodek P, Rocker G, et al. What matters most in end-of-life care: perceptions of seriously ill patients and their family members. CMAJ 2006;174:627-33.

27. Heyland DK, Dodek $P$, Mehta $S$, et al. Admission of the very elderly to the intensive care unit: Family members' perspectives on clinical decision-making from a multicenter cohort study. Palliat Med 2015;29:324-35.

28. Rady MY, Johnson DJ. Admission to intensive care unit at the end-of-life: is it an informed decision? Palliat Med 2004;18:705-11.

29. Chapple HS. No place for dying. Hospitals and the ideology of rescue. Walnut Creek, CA: Left Coast Press, 2010.

30. Mitchell AJ, Chan M, Bhatti $\mathrm{H}$, et al. Prevalence of depression, anxiety, and adjustment disorder in oncological, haematological, and palliative-care settings: a meta-analysis of 94 interview-based studies. Lancet Oncol 2011;12:160-74.

31. Stacey D, Legare F, Pouliot S, et al. Shared decision making models to inform an interprofessional perspective on decision making: a theory analysis. Patient Educ Couns 2010;80:164-72.

32. Legare F, Stacey D, Gagnon S, et al. Validating a conceptual model for an interprofessional approach to shared decision-making: a mixed methods study. J Eval Clin Practice 2011;17:554-64.

33. Song J, Bartels DM, Ratner ER, et al. Dying on the streets: homeless persons' concerns and desires about end of life care. $J$ Gen Intern Med 2007;22:435-41.

34. McNeil R, Guirguis-Younger M. Illicit drug use as a challenge to the delivery of end-of-life care services to homeless persons: perceptions of health and social services professionals. Palliat Med 2012;26:350-9.

35. Ko E, Kwak J, Nelson-Becker H. What constitutes a good and bad death?: Perspectives of homeless older adults. Death Stud 2015;39:422-32.

36. Wiese M, Stancliffe RJ, Balandin S, et al. End-of-life care and dying: issues raised by staff supporting older people with intellectual disability in community living services. J Appl Res Intellect Disabil 2012;25:571-83.

37. Seaman JB, Bear TM, Documet PI, et al. Hospice and family involvement with end-of-life care: results from a population-based survey. Am J Hosp Palliat Care 2016;33:130-5.

38. Burton $\mathrm{CR}$, Payne S. Integrating palliative care within acute stroke services: developing a programme theory of patient and family needs, preferences and staff perspectives. BMC Palliat Care 2012;11:22.

39. Forero R, McDonnell G, Gallego B, et al. A literature review on care at the end-of-life in the emergency department. Emerg Med Int 2012;2012:486516.

40. Kryworuchko J, Stacey D, Peterson WE, et al. A qualitative study of family involvement in decisions about life support in the intensive care unit. Am J Hosp Palliat Care 2012;29:36-46.

41. Gajera M, Kalra A, Butler I, et al. Provider perceptions of end of life (EOL) discussion in the intensive care unit (ICU): impact of EOL bundle. Crit Care Med 2010;38:A203. 
42. Daly BJ, Douglas SL, O'Toole E, et al. Effectiveness trial of an intensive communication structure for families of long-stay ICU patients. Chest 2010;138:1340-8.

43. Hickman SE, Keevern E, Hammes BJ. Use of the physician orders for life-sustaining treatment program in the clinical setting: a systematic review of the literature. J Am Geriatr Soc 2015;63: 341-50.

44. Arnold RM, Back AL, Barnato AE, et al. The Critical Care Communication project: improving fellows' communication skills. J Crit Care 2015;30:250-4.

45. Visser M, Deliens L, Houttekier D. Physician-related barriers to communication and patient- and family-centred decision-making towards the end of life in intensive care: a systematic review. Crit Care 2014;18:604.

46. Zwarenstein M, Rice K, Gotlib-Conn L, et al. Disengaged: a qualitative study of communication and collaboration between physicians and other professions on general internal medicine wards. BMC Health Serv Res 2013;13:494-494.

47. Reeves S, Perrier L, Goldman J, et al. Interprofessional education: effects on professional practice and healthcare outcomes (update). Cochrane Database Syst Rev 2013;3:CD002213.

48. McCallister JW, Gustin JL, Wells-Di Gregorio S, et al.

Communication skills training curriculum for pulmonary and critical care fellows. Ann Am Thorac Soc 2015;12:520-5. 